\title{
Localized bone regeneration around dental implants using recombinant bone morphogenetic protein-2 and platelet-derived growth factor-BB in the canine
}

\author{
Thoma, Daniel S ; Cha, Jae-Kook ; Sapata, Vitor M ; Jung, Ronald E ; Hüsler, Juerg ; Jung, Ui-Won
}

\begin{abstract}
OBJECTIVES To test whether or not one of two biological mediators (recombinant human bone morphogenetic protein-2 (rhBMP-2) and recombinant human platelet-derived growth factor (rhPDGF-BB)) is superior to the other and compared with control groups for bone regeneration around implants based on histomorphometrical outcome measures. MATERIALS AND METHODS Box-type defects $(10 \times 5 \times 5 \mathrm{~mm})$ were prepared on the buccal sides of the left and right edentulous ridge in ten mongrel dogs. Implants were placed at each site, the defects either received (i) bovine-derived particulated bone mineral (DBBM) mixed with rhBMP-2 and a collagen membrane (CM) (DBBM/BMP-2), (ii) DBBM mixed with rhPDGF-BB and CM (DBBM/PDGF), (iii) DBBM and $\mathrm{CM}(\mathrm{DBBM})$ and (iv) empty control (control). Animals were euthanized post-surgery at 8 weeks and 16 weeks. Histomorphometrical analyses were performed. RESULTS The mean percentages of regenerated area within total defect area amounted to 56.95\% for DBBM/BMP-2, 48.86\% for DBBM/PDFG, 33.44\% for DBBM and $1.59 \%$ for control at 8 weeks, and $26.79 \%$ for DBBM/BMP-2, $23.78 \%$ for DBBM/PDFG, $30.21 \%$ for DBBM and $5.07 \%$ for control at 16 weeks with no statistically significant differences between the groups $(\mathrm{P}>0.05)$. The mean amount of regenerated bone was $26.97 \%$ for DBBM/BMP-2, 22.02\% for DBBM/PDFG, 5.03\% for DBBM and $1.25 \%$ for control at 8 weeks, and at 16 weeks, these values were lower in the two groups with biological mediators (DBBM/BMP$2=13.35 \%$; DBBM/PDGF $=6.96 \%)$ and only slightly increased in group DBBM $(10.68 \%)$ and the control group (4.95\%) compared with 8 weeks. The first bone-to-implant contact values on the buccal side were minimal for DBBM/BMP-2 $(0.57 \mathrm{~mm})$ and maximal for control $(3.72 \mathrm{~mm})$ at 8 weeks. CONCLUSIONS The use of biological mediators (rhBMP-2 and rhPDGF-BB) can increase the amount of bone regeneration at dehiscence-type defects compared with controls at 8 weeks, but not at 16 weeks due to enhanced hard tissue remodeling processes.
\end{abstract}

DOI: https://doi.org/10.1111/clr.12989

Posted at the Zurich Open Repository and Archive, University of Zurich

ZORA URL: https://doi.org/10.5167/uzh-131022

Journal Article

Accepted Version

Originally published at:

Thoma, Daniel S; Cha, Jae-Kook; Sapata, Vitor M; Jung, Ronald E; Hüsler, Juerg; Jung, Ui-Won (2017). Localized bone regeneration around dental implants using recombinant bone morphogenetic protein-2 and platelet-derived growth factor-BB in the canine. Clinical Oral Implants Research, 28(11):1334-1341.

DOI: https://doi.org/10.1111/clr.12989 
Localized bone regeneration around dental implants using recombinant bone morphogenetic protein-2 and platelet-derived growth factor-BB in the canine.

Thoma DS ${ }^{1}$, Cha $\mathrm{JK}^{2}$, Sapata VM, ${ }^{1}$ Jung $\mathrm{RE}^{1}$, Hüsler $\mathrm{J},{ }^{1}$ Jung $\mathrm{UW}^{2}$

${ }^{1}$ Clinic for Fixed and Removable Prosthodontics and Dental Material Science, University of Zurich, Zurich, Switzerland

2 Department of Periodontology, Research Institute for Periodontal Regeneration, Yonsei University College of Dentistry, Seoul, Korea

Key words: bone augmentation, platelet-derived growth factor-BB, bone morphogenetic protein-2, deproteinized bovine bone mineral, dental implants

Running title: GBR using rhBMP-2 and rhPDGF-BB

Address for correspondence:

Ui-Won Jung, PhD. DDS.

Department of Periodontology, Yonsei University College of Dentistry

50-1 Yonseiro Seodaemungu, Seoul, 120-752, South Korea

Phone: +82 2 2228-3185

Fax: +82 23920398

e-mail: drjew@yuhs.ac 


\section{Abstract}

Objectives: To test whether or not one out two biologic mediators (recombinant human bone morphogenetic protein-2 (rhBMP-2) and recombinant human platelet-derived growth factor (rhPDGF-BB)) is superior to the other and compared to control groups for bone regeneration around implants based on histomorphometric outcome measures.

Materials and methods: Box-type defects $(10 \times 5 \times 5 \mathrm{~mm})$ were prepared on the buccal sides of the left and right edentulous ridge in ten mongrel dogs. Implants were placed at each site, the defects either received (i) bovine-derived particulated bone mineral (DBBM) mixed with rhBMP2 and a collagen membrane (CM) (DBBM/BMP-2), (ii) DBBM mixed with rhPDGF-BB and CM (DBBM/PDGF), (iii) DBBM and CM (DBBM), and (iv) empty control (control). Animals were euthanized post-surgery at 8 weeks and 16 weeks. Histomorphometric analyses were performed.

Results: The mean percentages of regenerated area within total defect area amounted to $56.95 \%$ for DBBM/BMP-2, 48.86\% for DBBM/PDFG, 33.44\% for DBBM and $1.59 \%$ for control at 8 weeks, and at 16 weeks $26.79 \%$ for DBBM/BMP-2, $23.78 \%$ for DBBM/PDFG, $30.21 \%$ for DBBM and $5.07 \%$ for control with no statistically significant differences between the groups ( $p>0.05$ ). The mean amount of regenerated bone was $26.97 \%$ for DBBM/BMP-2, $22.02 \%$ for DBBM/PDFG, $5.03 \%$ for DBBM and $1.25 \%$ for control at 8 weeks and at 16 weeks, these values were lower in the two groups with biological mediators (DBBM/BMP-2=13.35\%; DBBM/PDGF $=6.96 \%)$ and only slightly increased in group DBBM $(10.68 \%)$ and the control group (4.95\%) compared to 8 weeks. The first bone to implant contact values on the buccal side were minimal for DBBM/BMP-2 $(0.57 \mathrm{~mm})$ and maximal for control $(3.72 \mathrm{~mm})$ at 8 weeks.

Conclusions: The use of biologic mediators (rhBMP-2, rhPDGF-BB) can increase the amount of bone regeneration at dehiscence-type defects compared to controls at 8 weeks, but not at 16 weeks due to enhanced hard tissue remodeling processes. 



\section{Introduction}

Guided bone regeneration (GBR) procedures are routinely performed in dental practice to regenerate missing hard and soft tissue volume prior to or simultaneously with dental implant placement (Hämmerle et al. 2002; Bornstein et al. 2008). For that purpose, autogenous bone or bone substitute materials in combination with non-resorbable barrier membranes are used. These membranes offer advantages in terms of the stability of the augmented site and render high clinical success rates (Friedmann et al. 2001; von Arx et al. 2001; Buser et al. 2002). Though, clinical disadvantages include: an additional surgical procedure to remove the membrane and increased rates of membrane exposure (Becker et al. 1994; Simion et al. 1994; Strietzel 2001). In order to overcome these shortcomings, resorbable membranes were introduced. Among these, collagen membranes are well documented and have shown to render high success rates (Pitaru et al. 1987; Zitzmann et al. 1997; Zitzmann et al. 2001; Hockers et al. 1999; Friedmann et al. 2001). However, these relatively soft membranes do not maintain space per se and a compression of the regenerated site can potentially result in a displacement of the augmentation material (Strietzel et al. 2006).

More recently, bone regeneration was performed applying the principles of tissue engineering (Gothard et al. 2014), focused on the investigation of bioactive molecules to induce local bone formation. Based on a number of systematic reviews, the most promising factors for localized ridge augmentation include recombinant human bone morphogenetic protein-2 (rhBMP-2) and recombinant platelet-derived growth factor (rhPDGF-BB) (Jung, Thoma \& Hämmerle 2008; Fisher et al. 2013; Khojasteh et al. 2013).

RhBMP-2 promotes better results on ridge regeneration following socket grafting (Lee et al. 2015) and bone regeneration and osseointegration around dental implants (Jung et al. 2003, 2009; Jung et al. 2015; Kim et al. 2015). RhPDGF-BB has been employed in the field of periodontology in combination with various carrier materials for the treatment of infrabony defects (Nevins et al. 2005, 2013; Jayakumar et al. 2011; Thakare \& Deo 2012; Khoshkam et al. 2015). In implant dentistry, rhPDGF-BB has been used to enhance bone formation in localized bone defects and for vertical ridge augmentation (Simion et al. 2006; Simion et al. 2007; Nevins 
et al. 2009, 2012; McAllister et al. 2010; Thoma et al. 2012; Xu et al. 2016).

Whereas both, rhBMP-2 and rhPDGF-BB have been successfully used in various animal models and clinical applications (Boyan et al. 2000; Cochran et al. 2000; Jung et al. 2003; Simion et al. 2006; Thoma et al. 2010; Darby \& Morris 2013), no data can be retrieved from the literature comparing the two biological mediators for guided bone regeneration around dental implants in the same experimental model.

Therefore, the aims of the study were to test whether or not one out of two biological mediators (rhPDGF-BB or rhBMP-2) is superior to the other and compared to control groups for bone regeneration around implants based on histological and histomorphometric outcome measures. 


\section{Materials and Methods}

The study was designed as a randomized experimental study employing 10 healthy adult beagle dogs (weight $=15 \mathrm{~kg}$ ). The animals were kept in a purpose-designed room for experimental animals and were fed a standard laboratory diet. The study was approved by the institutional animal care and use committee of Yonsei medical center, Seoul, Korea (permission no.: 2013-0317).

All the materials used in the present study are commercially available. Preparation of rhBMP-2 (Cowellmedi, Busan, Republic of Korea) was similar to a previous report (Jung et al. 2015). RhPDGF-BB (GEM 21S $\AA$, Osteohealth, BioMimetic Therapeutics Inc., USA) was purchased from the manufacturer.

\section{Surgical Procedure}

The surgical procedure has been described in the previous report (Jung et al. 2015). In brief, all surgical procedures were performed under general anesthesia. Subsequently, local infiltration anesthesia was additionally injected at the surgical site.

\section{Surgery 1}

After mucoperiostal flaps were reflected bilaterally in the mandible, the third and fourth premolar as well as the first molar (P3, P4, M1) were carefully removed. Primary wound closure was obtained using monofilament sutures (Monosyn ${ }^{\circledR} 4.0$ Glyconate Monofilament, B. Braun Tuttlingen, Germany). Additional medications were administrated after the surgeries, including an antibiotic prophylaxis (Moxicle, Daewoong Pharm., Gyeonggido, Korea), an antiinflammatory and an analgesic drug (Ketorolac, Hana Pharm., Gyeonggido, Korea; Meloxicam, Boehringer Ingelheim, Bogota D.C., Colombia) for 7 days.

\section{Surgery 2}

After three months of healing, defect preparation, implant placement and GBR procedures were performed in all dogs. Following a mid-crestal incision, mucoperiostal flaps were reflected to expose the buccal and lingual alveolar plate. A vertical releasing incision was placed distal to the canine. All granulation tissue was carefully removed and the edentulous 
ridge was flattened to obtain a width of at least $7 \mathrm{~mm}$. Two implant sites were prepared bilaterally under abundant irrigation with sterile saline, at a distance of $14 \mathrm{~mm}$ apart and at the same distance from the buccal cortical bone plate. Following implant site preparation, two standardized box-shaped defects (mesio-distal width: $10 \mathrm{~mm}$, depth: $5 \mathrm{~mm}$, height: $5 \mathrm{~mm}$ ) were prepared bilaterally at the buccal aspect of the mandibular alveolar ridge (Fig. 1a \& b). The defect sites were standardized using a periodontal probe and rinsed with sterile saline to completely remove any residual debris. Thereafter, screw-type titanium implants (length $8 \mathrm{~mm}$, diameter $4.0 \mathrm{~mm}$, Astra Tech, OsseoSpeed ${ }^{\mathrm{TM}}$ TX $4.0 \mathrm{~S}$, DENTSPLY Implants, Mölndal, Sweden) were inserted with good primary stability in a way that the implant shoulder coincided with the bone crest at the lingual aspect. Titanium closure screws were applied.

The buccal dehiscence-type defects were allocated based on a computer software generated randomization list and the use of sealed envelopes. The treatment modalities were applied:

i. DBBM/BMP-2 group: Deproteinized bovine bone mineral (DBBM; BioOss $®$ granules, particle size 0.25-1 mm, Geistlich, Wolhusen, Switzerland) mixed with rhBMP-2 (Cowellmedi, Busan, Republi of Korea) + collagen membrane (CM; BioGide ${ }^{\circledR}$, Geistlich, Wolhusen, Switzerland).

ii. DBBM/PDGF group: DBBM mixed with rhPDGF-BB (GEM 21S $®$, Osteohealth, BioMimetic Therapeutics Inc., USA) + CM.

iii. DBBM group: DBBM + CM.

iv. Control group: no treatment .

At the sites allocated for the use of bone substitutes, the defects were filled with a standardized amount of biomaterial (DBBM). For the DBBM/BMP-2 and DBBM/PDGF groups, $0.1 \mathrm{ml}$ of rhBMP-2 (Cowellmedi, Busan, Korea) or rhPDGF-BB (GEM 21S ${ }^{\circledR}$, Osteohealth, BioMimetic Therapeutics Inc., USA) at a concentration of $0.3 \mathrm{mg} / \mathrm{ml}$ was loaded onto $0.07 \mathrm{~g}$ of DBBM granules (BioOss ${ }^{\circledR}$, Geistlich Biomaterials, Wolhusen, Switzerland), respectively. Three minutes of binding time was provided for both groups. For the DBBM group, $0.1 \mathrm{ml}$ of saline was 
mixed with DBBM. The DBBM biomaterial was covered with a CM in order extending $2 \mathrm{~mm}$ beyond the defect margins (Fig. 1c, d \& e). Before applying the membrane, the horizontal defect extensions were measured from the buccal implant surface to the most buccal aspect of the graft material. Bleeding was allowed to form a blood clot in empty sites, where no further treatment was applied. Resorbable polylactide pins (Inion CPS, Inion Ltd., Tampere, Finland) were inserted apically at all the sites in order to stabilize the membranes.

Following periosteal-releasing incisions, the mucoperiostal flaps were advanced coronally and primary wound closure was achieved by placing horizontal mattress sutures and interrupted sutures (4-0 Monosyn Glyconate Monofilament; B. Braun, Tuttlingen, Germany). The sutures were removed 14 days after surgery 2.

After a healing period of 2 months $(n=5)$ and 4 months $(n=5)$, the animals were terminated by an overdose of potassium chloride $3 g$ (Daihan Potassium chloride-40, Daihan pharm., Ansan, Korea). The jaws were dissected and blocks containing the experimental specimens with intact soft tissues were obtained.

\section{Histological preparation}

The specimens were fixed in $10 \%$ formalin for 2 weeks. An EXAKT cutting system (EXAKT® Apparatebau, Norderstedt, Germany) was used to cut the specimens at the center of the implant in a mesio-distal direction. The specimens were dehydrated in an ascending series of alcohol and subsequently embedded in methacrylate-based resin, polymerized and then fixed to the vacuum head of the EXAKT macro cutter. The thickness of sections was prepared with approximately $100 \mu \mathrm{m}$ and then ground and polished on the EXAKT micro grinder to a thickness of $15 \mu \mathrm{m}$. Paragon was used to stain the microscope slides.

\section{Histomorphometrical analysis}

Computer-assisted histomorphometric measurements were obtained using an automated image analysis system (LAS V4.3, Leica Microsystems, Wetzlar, Germany), coupled with a photo camera (Leica DFC450, Leica Microsystems, Wetzlar, Germany) mounted on a light microscope (Leica DM6000 B, Leica Microsystems, Wetzlar, Germany). 
In the central sections, the region of interest (ROI) was determined (Fig. 2a) and the following parameters were calculated (Fig. $2 b$ \& c):

-Total defect area $\left(\mathrm{mm}^{2} ; \mathrm{TDA}\right)$;

-Regenerated area $\left(\mathrm{mm}^{2} ; \mathrm{RA}\right)$;

-Percentage of regenerated area within total defect area (\%; RA/TDA);

-The percentage of regenerated bone, bone substitute material, mineralized tissue (bone + bone substitute material), soft tissue and background within TDA (\%);

-The first bone to implant contact ( $\mathrm{mm}$; fBIC), measured from the implant shoulder to the first bone to implant contact on the buccal $\left(f B \mid C_{b}\right)$ and lingual $\left(f B \mid C_{\mid}\right)$side.

\section{Statistical Analysis}

The metric variables were described with mean, median, standard deviation and quartiles. The comparisons of the four group means for the metric variables were performed using mixed linear models since the data within a dog were dependent (clustered). The dog was set as random effect in these models. The assumptions of these models were validated also in view of the small sample sizes. 


\section{Results}

The animals did not present signs of postoperative infections or weight reduction. There were no local complications in surgical areas during the entire study period.

\section{Descriptive histology}

All implants were well-osseointegrated. In the majority of the sites, the most coronal bone-to implant contact was close to the implant shoulder on the lingual side. On the buccal side, in a majority of sites, the fBIC was located more apical compared to the lingual side. In all sites, the soft tissues covered the implants, even in cases with implants threads not being covered with mineralized tissue. Within the augmented area, angiogenesis was observed in all groups at 8 and 16 weeks. In empty sites, this revascularization was predomiantly close to the implant surface and the apical border of the defect, whereas in all other groups (all with DBBM), newly formed blood vessels surrounded the DBBM particles. A relatively small number of osteoclasts was located at bone and bone substitute surfaces at 8 weeks. This number increased over the next 8 weeks.

In BMP-2 sites, at 8 weeks, the contour was mostly re-established (Fig. 3a). DBBM particles were completely surrounded by woven and lamellar bone. The mucosa did not show a collapse of the contour. At 16 weeks, the contour changed and presented a loss (Fig. 4a). Moreover, most of the DBBM particles were not present anymore. Lamellar bone formation was limited, mostly close to the implant surface.

At 8 weeks, in PDGF sites, the contour was mostly re-established with the augmented area being filled with DBBM particles and woven bone (Fig. 3b). In contrast to DBBM sites, bone formation was not limited to the implant surface, but was also evident surrounding the DBBM particles. At 16 weeks, part of the contour was lost in most cases, the amount of DBBM particles appeared to be less. Moreover, only limited woven and some lamellar bone was observed (Fig. $4 b)$.

In DBBM sites, the ridge contour was re-established in most cases, without obvious differences between the time-points (Fig. 3c \& 4c). Woven bone formation was evident along 
the implant surface, increasing from 8 to 16 weeks. At 8 weeks, the bone-to-bone substitute contact was very limited, whereas at 16 weeks, new bone formation (woven and lamellar bone) was evident around the DBBM particles.

In empty sites at both time-points ( 8 and 16 weeks), the ridge contour was not reestablished demonstrating exposed implant threads on roughly $50 \%$ of the implant surface (Fig. $3 d \& 4 d)$. Moreover, in a majority of the sites, the vertical dimension of the bone defect was even larger compared to the originally established defect dimension. Bone formation at the implant surface was not evident. The soft tissues, however, covered all implants, but the mucosa appeared to be collapsed.

\section{Histomorphometrical analysis}

All data are presented in table 1 and table 2 . The mean RA/TDA values amounted to $56.95 \% \pm 15.84 \%$ for DBBM/BMP-2, $48.86 \% \pm 19.81 \%$ for DBBM/PDFG, $33.44 \% \pm 14.09 \%$ for DBBM and $1.59 \% \pm 2.84 \%$ for control at 8 weeks. The control group demonstrated statistically significantly less RA/TDA at 8 weeks compared to all other groups ( $p<0.0001$ vs. DBBM/BMP-2, $p=0.0014$ vs. DBBM/PDGF and $p=0.0017$ vs. DBBM group). At 16 weeks, mean RA/TDA values were $26.79 \% \pm 19.83 \%$ for DBBM/BMP-2, $23.78 \% \pm 22.84 \%$ for DBBM/PDFG, $30.21 \% \pm 29.14 \%$ for DBBM and $5.07 \% \pm 8.91 \%$ for control. At 16 weeks, no statistically significant mean differences were found between the groups $(p>0.05)$.

The mean amount of regenerated bone was $26.97 \% \pm 12.17 \%$ for DBBM/BMP-2, $22.02 \% \pm 19.66 \%$ for DBBM/PDFG, $5.03 \% \pm 4.30 \%$ for DBBM and $1.25 \% \pm 2.60 \%$ for control at 8 weeks. The control and DBBM groups demonstrated statistically significant differences in terms of newly formed bone compared to DBBM/BMP-2 ( $p=0.0096$ and $p=0.0025$, respectively). At 16 weeks, these values were lower in the two groups with biological mediators (DBBM/BMP-2: $13.35 \% \pm 11.54 \%$; DBBM/PDGF: $6.96 \% \pm 9.73 \%$ ) and only slightly increased in group DBBM $(10.68 \% \pm 13.78 \%)$ and the control group $(4.95 \% \pm 8.69 \%)$ compared to 8 weeks. No statistically significant differences were found at 16 weeks $(p>0.05)$.

The mean values for residual bone substitute material were similar in all groups at both 
time-points $(p>0.05)$. A slight loss, however, was observed comparing the 8 to the 16 -week time-point.

The percentage of mineralized tissue (bone + bone substitute material) ranged between $38.38 \% \pm 13.98 \%$ for DBBM/BMP-2 and $1.25 \% \pm 2.60 \%$ for control at 8 weeks. The control group demonstrated statistically significantly less mineralized tissue compared to the others groups $(p=0.0009$ vs. DBBM/BMP-2, $p=0.0124$ vs. DBBM/PDGF and $p=0.0040$ vs. DBBM group). At 16 weeks the values ranged between $20.91 \% \pm 15.70 \%$ for DBBM/BMP-2 and $4.95 \% \pm 8.69 \%$ for control.

The fBIC values on the buccal side were minimal for DBBM/BMP-2 $(0.57 \mathrm{~mm} \pm 1.07 \mathrm{~mm})$ and maximal for control $(3.72 \mathrm{~mm} \pm 2.09 \mathrm{~mm})$ at 8 weeks. The DBBM/BMP-2 group demonstrated a statistically significantly smaller fBIC value compared to the DBBM group $(p=0.0015)$ and the control group $(p=0.0087)$. At 16 weeks, no statistically significant differences were observed between the groups $(p>0.05)$. 


\section{Discussion}

The present experimental study demonstrated that the use of biological mediators significantly increased the regenerated area at 8 weeks compared to controls. At 16 weeks, however, the use of rhBMP-2 and rhPDGF-BB was not beneficial in terms of bone regeneration compared to the bone substitute material alone (DBBM).

Descriptive histology revealed that the use of biological mediators (rhBMP-2; rhPDGFBB) affected the regeneration process in a positive way up to 8 weeks. RhBMP-2 has shown to be beneficial in terms of bone regeneration using a variety of bone substitute materials and for various indications (Thoma et al. 2010; Khojasteh et al. 2013; Khoshkam et al. 2015; Lee et al. 2015). These findings are supported by a systematic review, showing the highest potential for new bone formation among other biological mediators, especially when rhBMP-2 was used in combination with an appropriate carrier material (Khojasteh et al. 2013). RhPDGF-BB was included in a recent systematic review with meta-analysis (Khoshkam et al. 2015). Based on five included studies evaluating the effects of rhPDGF significantly more bone formation was demonstrated compared to negative controls or carrier materials alone. This is supported by a further systematic review (Khojasteh et al. 2013) analyzing different types of biological mediators. In three of four studies, an advantage for rhPDGF-BB groups was observed compared to negative controls.

From a clinical point of view, the aim would be to re-establish the ridge contour. For that purpose, the relative augmented area (RA/TDA) was calculated. The results of the present study indicated, at 8 weeks, a significantly better performance for the DBBM/BMP-2 group compared to DBBM and the control group. The weakest regeneration was obtained in the negative control group. Over time, between 8 and 16 weeks, a major proportion of the regenerated area in both groups using biological mediators was lost. Similar results with rhBMP2 were reported in previous studies in dogs showing enhanced bone formation compared to the control group at 8 weeks (Wikesjö et al. 2004) and at 12 weeks (Jovanovic et al. 2007), but no significant differences at 16 weeks (Smeets et al. 2009). A study using rhPDGF-BB in dogs, on standardized mandibular defects, reported similar results compared to a DBBM/PDGF group 
with a statistically significant higher mean augmented area compared to control sites at an early time-point (3 weeks) (Schwarz et al. 2009).

The amount of regenerated bone and the extent of bone formation along the implant surface represent useful parameters to qualitatively assess the regenerated area. At 8 weeks, significantly more bone formation was observed for DBBM/BMP-2 compared to DBBM and the negative control group, but not compared to the DBBM/PDGF group. In line with a major loss of volume over time, both groups with biologic mediators revealed an extensive reduction in the amount of regenerated bone in order of $50.5 \%$ for the DBBM/BMP-2 group and $68.4 \%$ for the DBBM/PDGF group between 8 and 16 weeks. These outcomes are lined up with the reduction of mineralized tissue and bone substitute material. There was a decrease of mineralized tissue (45.5\% for the DBBM/BMP-2, 56.8\% for DBBM/PDGF and 3.2\% for DBBM) and bone substitute material $(33.7 \%$ for the DBBM/BMP-2, $35.9 \%$ for DBBM/PDGF and $43.2 \%$ for DBBM) in augmented groups between 8 and 16 weeks. This generalized loss could be due to the lack of a more stable and durable membrane. Previous study demonstrated that the carrier material plays a crucial role (Sigurdsson et al. 1996). In case non-space-maintaining collagen sponges are used, bone regeneration using rhBMP-2 is limited (Barboza et al. 2000).

The $\mathrm{fBICb}$ showed more favorable results for the DBBM/BMP-2 group, with statistically significant differences compared to DBBM and control groups. No differences were found between the others groups. At 16 weeks the groups with biological mediators lost a considerable amount of bone, and the DBBM and control groups continued to improve the bone formation, resulting in no statistically significant differences. These outcomes corroborate with the relative augmented area (RA/TDA), regenerated bone and mineralized tissue results, where the new bone formation was faster on sites exposed to biological mediators, especially with rhBMP-2. At 16 weeks, no positive effect for the use of biologic mediators was observed. For DBBM/BMP-2, this could be explained by the short biological half-life, localized action and rapid local clearance (Kokubo et al. 2003). Clinically it is important to emphasize that the differences between DBBM/BMP-2 and the other groups were at least $1 \mathrm{~mm}$ for $\mathrm{fBIC}$, or $20 \%$ of the total defect height. This difference, even though no statistically significantly different, might have a 
clinical relevance. The fBIC values for the DBBM/BMP-2 group were in line with previous publications (Yamashita et al. 2010; Thoma et al. 2010) using rhBMP-2 and smaller compared to control groups.

The way rhBMP-2 and rhPDGF-BB interact with the surrounding tissues are substantially different. Both factors can act locally, but may also act systemically to affect the growth and function of distant cells and tissues. RhPDGF-BB is a so-called proliferation factor mainly having a mitogenic function and thereby increasing the number of cells in the area. In contrast, rhBMP-2 is a differentiation and primarily responsible for the maturation of cells. The specific function of the two biologic mediators may at least in part explain the obtained data in the present study. At the earlier time-point, the overall response in terms of bone regeneration was stronger for rhBMP-2 compared to rhPDGF-BB and probably owing to a strong induction of osteoblast differentiation. RhPDGF-BB, however, did improve the outcomes in terms of bone regeneration compared to the bone substitute material alone, probably due to a its function of being mitogenic and enhancing angiogenesis. 


\section{Conclusions}

Within the limitations of the present experimental study, the use of biologic mediators (rhBMP-2, rhPDGF-BB) can increase the amount of bone regeneration at dehiscence-type defects compared to controls at 8 weeks. The augmented area may undergo enhanced hard tissue remodeling processes during further healing preventing any clinical benefit for the use of biologic mediators compared to control groups at a later time-point.

\section{Acknowledgements}

The help and support of Ms. Sora Yoon and Dr. Jin-Young Park at the Department of Periodontology, Yonsei University is greatly appreciated.

This study was supported by the Basic Science Research Program of the National Research Foundation of Korea (NRF) funded by the Ministry of Education (No.NRF2014R1A1A1A05002953).

\section{Conflict of interest}

The authors report no conflict of interest. 


\section{REFERENCES}

von Arx, T., Cochran, D.L., Hermann, J.S., Schenk, R.K., Higginbottom, F.L. \& Buser, D. (2001) Lateral Ridge Augmentation and Implant Placement: An Experimental Study Evaluating Implant Osseointegration in Different Augmentation Materials in the Canine Mandible. The International Journal of Oral \& Maxillofacial Implants 16: 343-354.

Barboza, E.P., Duarte, M.E.L., Geolás, L., Sorensen, R.G., Riedel, G.E. \& Wikesjö, U.M.E. (2000) Ridge Augmentation Following Implantation of Recombinant Human Bone Morphogenetic Protein-2 in the Dog. Journal of Periodontology 71: 488-496.

Becker, W., Dahlin, C., Becker, B.E., Lekholm, U., van Steenberghe, D., Higuchi, K., et al. (1994) The Use of e-PTFE Barrier Membranes for Bone Promotion Around Titanium Implants Placed Into Extraction Sockets: A Prospective Multicenter Study. The International Journal of Oral \& Maxillofacial Implants 9: 31-40.

Bornstein, M.M., Halbritter, S., Harnisch, H., Weber, H.P. \& Buser, D. (2008) A Retrospective Analysis of Patients Referred for Implant Placement to a Specialty Clinic: Indications, Surgical Procedures, and Early Failures. The International Journal of Oral \& Maxillofacial Implants 23: 1109-1116.

Boyan, B.D., Weesner, T.C., Lohmann, C.H., Andreacchio, D., Carnes, D.L., Dean, D.D., et al. (2000) Porcine fetal enamel matrix derivative enhances bone formation induced by demineralized freeze dried bone allograft in vivo. Journal of Periodontology 71: 12781286.

Buser, D., Ingimarsson, S., Dula, K., Lussi, A., Hirt, H.P. \& Belser, U.C. (2002) Long-Term Stability of Osseointegrated Implants in Augmented Bone: A 5-Year Prospective Study in Partially Edentulous Patients. International Journal of Periodontics \& Restorative Dentistry 22: 108-117.

Cochran, D.L., Jones, A.A., Lilly, L.C., Fiorellini, J.P. \& Howell, H. (2000) Evaluation of recombinant human bone morphogenetic protein-2 in oral applications including the use of endosseous implants: 3-year results of a pilot study in humans. Journal of 
Periodontology 71: 1241-1257.

Darby, I.B. \& Morris, K.H. (2013) A Systematic Review of the Use of Growth Factors in Human Periodontal Regeneration. Journal of Periodontology 84: 465-476.

Fisher, D.M., Min-Leong, Wong J., Crowley, C. \& Khan, W.S. (2013) Preclinical and clinical studies on the use of growth factors for bone repair: a systematic review. Current stem cell research \& therapy 8: 260-268.

Friedmann, A., Strietzel, F.P., Maretzki, B., Pitaru, S. \& Bernimoulin, J.P. (2001) Observations on a New Collagen Barrier Membrane in 16 Consecutively Treated Patients. Clinical and Histological Findings. Journal of Periodontology 72: 1616-1623.

Gothard, D., Smith, E.L., Kanczler, J.M., Rashidi, H., Qutachi, O., Henstock, J., et al. (2014) Tissue engineered bone using select growth factors: a comprehensive review of animal studies and clinical translation studies in man. European Cells and Materials 28: 166208.

Hämmerle, C.H.F., Jung, R.E. \& Feloutzis, A. (2002) A systematic review of the survival of implants in bone sites augmented with barrier membranes (guided bone regeneration) in partially edentulous patients. Journal of Clinical Periodontology 29: 226-231.

Hockers, T., Abensur, D., Valentini, P., Legrand, R. \& Hämmerle, C.H.F. (1999) The combined use of bioresorbable membranes and xenografts or autografts in the treatment of bone defects around implants. A study in beagle dogs. Clinical Oral Implants Research 10: 487-498.

Jayakumar, A., Rajababu, P., Rohini, S., Butchibabu, K., Naveen, A., Reddy, P.K., et al. (2011) Multi-centre, randomized clinical trial on the efficacy and safety of recombinant human platelet-derived growth factor with $\beta$-tricalcium phosphate in human intra-osseous periodontal defects: PDGF improves tissue repair. Journal of Clinical Periodontology 38 : 163-172.

Jovanovic, S.A., Hunt, D.R., Bernard, G.W., Spiekermann, H., Wozney, J.M. \& Wikesjö, U.M.E. (2007) Bone reconstruction following implantation of rhBMP-2 and guided bone 
regeneration in canine alveolar ridge defects. Clinical Oral Implants Research 18: 224230.

Jung, R.E., Glauser, R., Schärer, P., Hämmerle, C.H.F., Sailer, H.F. \& Weber, F.E. (2003) Effect of rhBMP-2 on guided bone regeneration in humans. Clinical oral implants research 14: 556-568.

Jung, R.E., Thoma, D.S. \& Hammerle, C.H.F. (2008) Assessment of the potential of growth factors for localized alveolar ridge augmentation: a systematic review. Journal of Clinical Periodontology 35: 255-281.

Jung, R.E., Windisch, S.I., Eggenschwiler, A.M., Thoma, D.S., Weber, F.E. \& Hämmerle, C.H.F. (2009) A randomized-controlled clinical trial evaluating clinical and radiological outcomes after 3 and 5 years of dental implants placed in bone regenerated by means of GBR techniques with or without the addition of BMP-2. Clinical Oral Implants Research 20: 660-666.

Jung, U.W., Lee, I.K., Park, J.Y., Thoma, D.S., Hämmerle, C.H.F. \& Jung, R.E. (2015) The efficacy of BMP-2 preloaded on bone substitute or hydrogel for bone regeneration at peri-implant defects in dogs. Clinical Oral Implants Research 26: 1456-1465.

Khojasteh, A., Behnia, H., Naghdi, N., Esmaeelinejad, M., Alikhassy, Z. \& Stevens, M. (2013) Effects of different growth factors and carriers on bone regeneration: a systematic review. Oral Surgery, Oral Medicine, Oral Pathology and Oral Radiology 116: e405e423.

Khoshkam, V., Chan, H.L., Lin, G.H., Mailoa, J., Giannobile, W.V., Wang, H.L., et al. (2015) Outcomes of regenerative treatment with rhPDGF-BB and rhFGF-2 for periodontal intrabony defects: a systematic review and meta-analysis. Journal of Clinical Periodontology 42: $272-280$.

Kim, N.H., Lee, S.H., Ryu, J.J., Choi, K.H. \& Huh, J.B. (2015) Effects of rhBMP-2 on Sandblasted and Acid Etched Titanium Implant Surfaces on Bone Regeneration and Osseointegration: Spilt-Mouth Designed Pilot Study. BioMed Research International 
2015: 1-11.

Kokubo, S., Fujimoto, R., Yokota, S., Fukushima, S., Nozaki, K., Takahashi, K., et al. (2003) Bone regeneration by recombinant human bone morphogenetic protein-2 and a novel biodegradable carrier in a rabbit ulnar defect model. Biomaterials 24: 1643-1651.

Lee, J.-S., Jung, J.-S., Im, G.I., Kim, B.S., Cho, K.S. \& Kim, C.S. (2015) Ridge regeneration of damaged extraction sockets using rhBMP-2: an experimental study in canine. Journal of Clinical Periodontology 42: 678-687.

McAllister, B.S., Haghighat, K., Prasad, H.S. \& Rohrer, M.D. (2010) Histologic Evaluation of Recombinant Human Platelet-Derived Growth Factor-BB After Use in Extraction Socket Defects: A Case Series. International Journal of Periodontics \& Restorative Dentistry 30: $365-373$.

Nevins, M., Giannobile, W.V., McGuire, M.K., Kao, R.T., Mellonig, J.T., Hinrichs, J.E., et al. (2005) Platelet-Derived Growth Factor Stimulates Bone Fill and Rate of Attachment Level Gain: Results of a Large Multicenter Randomized Controlled Trial. Journal of Periodontology 76: 2205-2215.

Nevins, M., Hezaimi, K.A., Schupbach, P., Karimbux, N. \& Kim, D.M. (2012) Vertical Ridge Augmentation Using an Equine Bone and Collagen Block Infused With Recombinant Human Platelet-Derived Growth Factor-BB: A Randomized Single-Masked Histologic Study in Non-Human Primates. Journal of Periodontology 83: 878-884.

Nevins, M., Kao, R.T., McGuire, M.K., McClain, P.K., Hinrichs, J.E., McAllister, B.S., et al. (2013) Platelet-Derived Growth Factor Promotes Periodontal Regeneration in Localized Osseous Defects: 36-Month Extension Results From a Randomized, Controlled, Double-Masked Clinical Trial. Journal of Periodontology 84: 456-464.

Nevins, M.L., Camelo, M., Nevins, M., Schupbach, P., Friedland, B. \& Camelo, J.M.B. (2009) Minimally Invasive Alveolar Ridge Augmentation Procedure (Tunneling Technique) Using rhPDGF-BB in Combination with Three Matrices: A Case Series. International Journal of Periodontics \& Restorative Dentistry 29: 371-383. 
Pitaru, S., Tal, H., Soldinger, M., Azar-Avidan, O. \& Noff, M. (1987) Collagen membranes prevent the apical migration of epithelium during periodontal wound healing. Journal of Periodontal Research 22: 331-333.

Schwarz, F., Sager, M., Ferrari, D., Mihatovic, I. \& Becker, J. (2009) Influence of Recombinant Human Platelet-Derived Growth Factor on Lateral Ridge Augmentation Using Biphasic Calcium Phosphate and Guided Bone Regeneration: A Histomorphometric Study in Dogs. Journal of Periodontology 80: 1315-1323.

Sigurdsson, T.J., Nygaard, L., Tatakis, D.N., Fu, E., Turek, T.J., Jin, L., et al. (1996) Periodontal repair in dogs: evaluation of rhBMP-2 carriers. International Journal of Periodontics \& Restorative Dentistry 16: 524-537.

Simion, M., Baldoni, M., Rossi, P. \& Zaffe, D. (1994) A comparative study of the effectiveness of e-PTFE membranes with and without early exposure during the healing period. International Journal of Periodontics \& Restorative Dentistry 14: 166-180.

Simion, M., Rocchietta, I. \& Dellavia, C. (2007) Three-Dimensional Ridge Augmentation with Xenograft and Recombinant Human Platelet-Derived Growth Factor-BB in Humans: Report of Two Cases. International Journal of Periodontics \& Restorative Dentistry 27: $109-115$.

Simion, M., Rocchietta, I., Kim, D., Nevins, M. \& Fiorellini, J.P. (2006) Vertical Ridge Augmentation by Means of Deproteinized Bovine Bone Block and Recombinant Human Platelet-Derived Growth Factor-BB: A Histologic Study in a Dog Model. International Journal of Periodontics \& Restorative Dentistry 26: 415-423.

Smeets, R., Maciejewski, O., Gerressen, M., Spiekermann, H., Hanisch, O., Riediger, D., et al. (2009) Impact of rhBMP-2 on regeneration of buccal alveolar defects during the osseointegration of transgingival inserted implants. Oral Surgery, Oral Medicine, Oral Pathology, Oral Radiology, and Endodontology 108: e3-e12.

Strietzel, F.P. (2001) Risks and complications of membrane-guided bone regeneration. Retrospective analysis. Mund Kiefer Gesichtschirurgie 5: 28-32. 
Strietzel, F.P., Khongkhunthian, P., Khattiya, R., Patchanee, P. \& Reichart, P.A. (2006) Healing pattern of bone defects covered by different membrane types-A histologic study in the porcine mandible. Journal of Biomedical Materials Research Part B: Applied Biomaterials 78B: $35-46$.

Thakare, K. \& Deo, V. (2012) Randomized Controlled Clinical Study of rhPDGF-BB + $\beta-T C P$ Versus HA $+\beta-$ TCP for the Treatment of Infrabony Periodontal Defects: Clinical and Radiographic Results. International Journal of Periodontics \& Restorative Dentistry 32 : 689-696.

Thoma, D.S., Jones, A., Yamashita, M., Edmunds, R., Nevins, M. \& Cochran, D.L. (2010) Ridge Augmentation Using Recombinant Bone Morphogenetic Protein-2 Techniques: An Experimental Study in the Canine. Journal of Periodontology 81: 1829-1838.

Thoma, D.S., Jung, R.E., Hänseler, P., Hämmerle, C.H.F., Cochran, D.L. \& Weber, F.E. (2012) Impact of Recombinant Platelet-Derived Growth Factor BB on Bone Regeneration: A Study in Rabbits. International Journal of Periodontics \& Restorative Dentistry 32: 195202.

Wikesjö, U.M.E., Qahash, M., Thomson, R.C., Cook, A.D., Rohrer, M.D., Wozney, J.M., et al. (2004) rhBMP-2 significantly enhances guided bone regeneration. Clinical Oral Implants Research 15: 194-204.

Xu, L., Zhang, W., Lv, K., Yu, W., Jiang, X. \& Zhang, F. (2016) Peri-Implant Bone Regeneration Using rhPDGF-BB, BMSCs, and $\beta$-TCP in a Canine Model: rhPDGF-BB/BMSCs/ $\beta-T C P$ for Immediate Peri-Implant Bone Defects Repair. Clinical Implant Dentistry and Related Research 18: 241-252.

Yamashita, M., Nevins, M., Jones, A.A., Schoolfield, J. \& Cochran, D.L. (2010) A Pilot Experimental Lateral Ridge Augmentation Study Using Bone Morphogenetic Protein 2 in Dogs. International Journal of Periodontics \& Restorative Dentistry 30: 457-469.

Zitzmann, N.U., Naef, R. \& Schärer, P. (1997) Resorbable versus nonresorbable membranes in combination with Bio-Oss for guided bone regeneration. The International Journal of 
Oral \& Maxillofacial Implants 12: 844-852.

Zitzmann, N.U., Schärer, P. \& Marinello, C.P. (2001) Long-term Results of Implants Treated with Guided Bone Regeneration: A 5-year Prospective Study. The International Journal of Oral \& Maxillofacial Implants 16: 355-366. 


\section{Figure Legends}

Fig. 1. Clinical photographs of surgical procedures. Lateral view (a) and occlusal view (b) of box-type defects (mesio-distal width: $10 \mathrm{~mm}$, height: $5 \mathrm{~mm}$, depth: $5 \mathrm{~mm}$ ) with dental implants placed flush with the lingual bone crest. Occlusal view (c) bone substitute material placed into defect (right side); empty control (left side). Lateral view (d) of pinned collagen membrane (left side) and bone substitute material placed into defect (right side). Lateral view (e) of pinned collagen membrane (left side) and control site with blood clot (right side).

Fig. 2. Illustration of the region of interest (ROI; blue box) used for histomorphometric analysis (a). Illustration representing RA/TDA (light green area) (b). Illustration representing background (green), new bone formation (yellow), bone substitute material (blue) and connective tissue (dark red) (c).

Fig. 3. Histologic slide at $25 x$ magnification at 8 weeks. DBBM/BMP-2 group (a). DBBM/PDGF group (b). DBBM group (c). Control group (d). DBBM/BMP-2 = bovine-derived particulated bone mineral (DBBM) mixed with recombinant human bone morphogenetic protein-2 (rhBMP-2) and a collagen membrane (CM); DBBM/PDGF = DBBM mixed with recombinant platelet-derived growth factor (rhPDGF-BB) and CM; DBBM = DBBM and CM; control = empty control. $\mathrm{B}=$ native bone; NB=new bone formation; $B S=$ bone substitute material.

Fig. 4. Histologic slide at 25x magnification at 16 weeks. DBBM/BMP-2 group (a). DBBM/PDGF group (b). DBBM group (c). Control group (d). DBBM/BMP-2 = bovine-derived particulated bone mineral (DBBM) mixed with recombinant human bone morphogenetic protein-2 (rhBMP-2) and a collagen membrane (CM); DBBM/PDGF = DBBM mixed with recombinant platelet-derived growth factor (rhPDGF-BB) and CM; DBBM = DBBM and CM; control = empty control. $\mathrm{B}=$ native bone; NB=new bone formation; $B S=$ bone substitute material. 
Table

Table 1. Histomorphometrical analysis values at 8 weeks.

\begin{tabular}{|c|c|c|c|c|c|c|c|c|}
\hline & \multicolumn{2}{|c|}{ DBBM/BMP-2 } & \multicolumn{2}{|c|}{ DBBM/PDGF } & \multicolumn{2}{|c|}{ DBBM } & \multicolumn{2}{|c|}{ Control } \\
\hline & Mean (SD) & $\begin{array}{c}\text { Median } \\
\text { (Q1; Q3) } \\
\end{array}$ & Mean (SD) & $\begin{array}{c}\text { Median } \\
(\mathrm{Q} 1 ; \mathrm{Q} 3) \\
\end{array}$ & Mean (SD) & $\begin{array}{c}\text { Median } \\
(\mathrm{Q} 1 ; \mathrm{Q} 3)\end{array}$ & Mean (SD) & $\begin{array}{c}\text { Median } \\
\text { (Q1; Q3) }\end{array}$ \\
\hline TDA $\left(\mathrm{mm}^{2}\right)$ & $7.56(1.26)$ & $\begin{array}{c}7.34 \\
(7.04 ; 8.00)\end{array}$ & 7.07 (1.09) & $\begin{array}{c}7.50 \\
(6.21 ; 8.01)\end{array}$ & $5.89(1.23)$ & $\begin{array}{c}5.54 \\
(5.30 ; 5.75)\end{array}$ & $6.02(1.81)$ & $\begin{array}{c}4.73 \\
(4.70 ; 8.00)\end{array}$ \\
\hline $\mathrm{RA}\left(\mathrm{mm}^{2}\right)$ & $4.24(1.20)$ & $\begin{array}{c}4.11 \\
(3.12 ; 5.22)\end{array}$ & $3.57(1.76)$ & $\begin{array}{c}3.62 \\
(2.24 ; 5.12)\end{array}$ & $2.03(1.17)$ & $\begin{array}{c}1.60 \\
(1.20 ; 2.29)\end{array}$ & $0.07(0.13)$ & $\begin{array}{c}0.02 \\
(0.00 ; 0.05)\end{array}$ \\
\hline RA/TDA (\%) & $56.95(15.84)^{a}$ & $\begin{array}{c}58.41^{\mathrm{a}} \\
(51.08 ; 71.06)\end{array}$ & $48.86(19.81)^{a}$ & $\begin{array}{c}45.16^{\mathrm{a}} \\
(39.86 ; 63.90)\end{array}$ & $33.44(14.09)^{a}$ & $\begin{array}{c}30.18 \mathrm{a} \\
(21.60 \\
46.98)\end{array}$ & $1.59(2.84)$ & $\begin{array}{c}0.40 \\
(0.00 ; 0.95)\end{array}$ \\
\hline $\mathrm{fBICl}(\mathrm{mm})$ & $0.04(0.09$ & $\begin{array}{c}0.00 \\
(0.00 ; 0.00)\end{array}$ & $0.236(0.36)$ & $\begin{array}{c}0.00 \\
(0.00 ; 0.36)\end{array}$ & $0.12(0.27)$ & $\begin{array}{c}0.00 \\
(0.00 ; 0.00)\end{array}$ & $0.173(0.26)$ & $\begin{array}{c}0.00 \\
(0.00 ; 0.27)\end{array}$ \\
\hline fBICb (mm) & $0.57(1.07)^{a, b}$ & $\begin{array}{c}0.06 \mathrm{a}, \mathrm{b} \\
(0.00 ; 0.33)\end{array}$ & $\begin{array}{c}1.84 \\
(1.96)\end{array}$ & $\begin{array}{c}1.92 \\
(0.00 ; 2.64)\end{array}$ & 3.65 (1.62) & $\begin{array}{c}4.13 \\
(3.67 ; 4.74)\end{array}$ & $3.724(2.09)$ & $\begin{array}{c}4.68 \\
(4.39 ; 4.77)\end{array}$ \\
\hline $\mathrm{B}(\%)$ & $26.97 \underset{b}{(12.17)^{a}}$ & $\begin{array}{c}30.28 \mathrm{a}, \mathrm{b} \\
(28.76 ; 31.89)\end{array}$ & $\begin{array}{c}22.02 \\
(19.66)\end{array}$ & $\begin{array}{c}15.37 \\
(5.22 ; 39.72)\end{array}$ & $5.03(4.30)$ & $\begin{array}{c}2.57 \\
(2.46 ; 7.30)\end{array}$ & $1.25(2.60)$ & $\begin{array}{c}0.00 \\
(0.00 ; 0.37)\end{array}$ \\
\hline BS (\%) & $11.41(3.23)$ & $\begin{array}{c}9.48 \\
(9.10 ; 13.67)\end{array}$ & $\begin{array}{l}12.18 \\
(5.83)\end{array}$ & $\begin{array}{c}9.64 \\
(9.57 ; 12.10)\end{array}$ & $14.53(8.40)$ & $\begin{array}{c}17.19 \\
(7.01 ; 19.43)\end{array}$ & $0.00(0.00)$ & $\begin{array}{c}0.00 \\
(0.00 ; 0.00)\end{array}$ \\
\hline MT (\%) & $38.38(13.98)^{a}$ & $\begin{array}{c}41.00^{a} \\
(39.10 ; 42.43)\end{array}$ & $34.20(16.96)^{a}$ & $\begin{array}{c}27.47^{\mathrm{a}} \\
(27.40 ; 47.14)\end{array}$ & $19.56(8.60)^{a}$ & $\begin{array}{c}20.73^{a} \\
(11.96 ; \\
26.84)\end{array}$ & $1.25(2.60)$ & $\begin{array}{c}0.00 \\
(0.00 ; 0.37)\end{array}$ \\
\hline ST $(\%)$ & $56.81(17.41)$ & $\begin{array}{c}58.47 \\
(48.74 ; 60.60)\end{array}$ & $\begin{array}{c}58.32 \\
(18.41)\end{array}$ & $\begin{array}{c}67.46 \\
(47.41 ; 72.30)\end{array}$ & $77.04(9.22)$ & $\begin{array}{c}72.75 \\
(70.64 ; 85.43)\end{array}$ & $84.03(12.54)$ & $\begin{array}{l}86.00 \\
(74.66 ; \\
91.79)\end{array}$ \\
\hline
\end{tabular}

a: significantly different with control group ( $p<0.01)$; b: significantly different with DBBM group $(p<0.01)$.

Table 2. Histomorphometrical analysis values at 16 weeks 


\begin{tabular}{|c|c|c|c|c|c|c|c|c|}
\hline & \multicolumn{2}{|c|}{ DBBM/BMP-2 } & \multicolumn{2}{|c|}{ DBBM/PDGF } & \multicolumn{2}{|c|}{ DBBM } & \multicolumn{2}{|c|}{ Control } \\
\hline & Mean (SD) & $\begin{array}{c}\text { Median } \\
\text { (Q1; Q3) }\end{array}$ & Mean (SD) & $\begin{array}{c}\text { Median } \\
(\mathrm{Q} 1 ; \mathrm{Q} 3)\end{array}$ & Mean (SD) & $\begin{array}{c}\text { Median } \\
\text { (Q1; Q3) }\end{array}$ & Mean (SD) & $\begin{array}{c}\text { Median } \\
\text { (Q1; Q3) }\end{array}$ \\
\hline $\operatorname{TDA}\left(\mathrm{mm}^{2}\right)$ & $5.38(1.42)$ & $\begin{array}{c}4.89 \\
(4.80 ; 5.55)\end{array}$ & 5.64 (1.70) & $\begin{array}{c}5.93 \\
(4.29 ; 6.25)\end{array}$ & $6.32(1.57)$ & $\begin{array}{c}5.68 \\
(5.13 ; 8.00)\end{array}$ & $6.47(1.91)$ & $\begin{array}{c}7.51 \\
(4.78 ; 8.00)\end{array}$ \\
\hline $\mathrm{RA}\left(\mathrm{mm}^{2}\right)$ & $1.29(0.90)$ & $\begin{array}{c}1.72 \\
(0.42 ; 1.84)\end{array}$ & $1.34(1.45)$ & $\begin{array}{c}0.71 \\
(0.20 ; 2.72)\end{array}$ & $1.98(2.22)$ & $\begin{array}{c}2.18 \\
(0.08 ; 2.19)\end{array}$ & $0.25(0.42)$ & $\begin{array}{c}0.06 \\
(0.04 ; 0.12)\end{array}$ \\
\hline RA/TDA (\%) & $26.79(19.83)$ & $\begin{array}{c}33.17 \\
(8.69 ; 43.45)\end{array}$ & $23.78(22.84)$ & $\begin{array}{c}19.05 \\
(4.74 ; 45.75)\end{array}$ & $30.21(29.14)$ & $\begin{array}{c}38.38 \\
(1.67 ; 42.76)\end{array}$ & 5.07 (8.91) & $\begin{array}{c}0.80 \\
(0.59 ; 2.92)\end{array}$ \\
\hline $\mathrm{fBICl}(\mathrm{mm})$ & $0.11(0.13)$ & $\begin{array}{c}0.07 \\
(0.00 ; 0.19)\end{array}$ & $0.23(0.34)$ & $\begin{array}{c}0.00 \\
(0.00 ; 0.41)\end{array}$ & $0.02(0.05)$ & $\begin{array}{c}0.00 \\
(0.00 ; 0.00)\end{array}$ & $0.51(0.48)$ & $\begin{array}{c}0.30 \\
(0.27 ; 0.78)\end{array}$ \\
\hline $\mathrm{fBICb}(\mathrm{mm})$ & $1.46(1.28)$ & $\begin{array}{c}1.14 \\
(0.80 ; 1.81)\end{array}$ & 3.22 (1.73) & $\begin{array}{c}3.06 \\
(2.22 ; 4.46)\end{array}$ & $2.51(1.55)$ & $\begin{array}{c}2.91 \\
(1.04 ; 3.10)\end{array}$ & $3.40(1.81)$ & $\begin{array}{c}4.28 \\
(3.01 ; 4.31)\end{array}$ \\
\hline $\mathrm{B}(\%)$ & $13.35(11.54)$ & $\begin{array}{c}8.68 \\
(6.44 ; 19.61)\end{array}$ & $6.96(9.73)$ & $\begin{array}{c}2.51 \\
(0.78 ; 8.13)\end{array}$ & $10.68(13.78)$ & $\begin{array}{c}9.72 \\
(0.00 ; 9.98)\end{array}$ & 4.95 (8.69) & $\begin{array}{c}0.72 \\
(0.58 ; 2.94)\end{array}$ \\
\hline BS (\%) & $7.56(6.38)$ & $\begin{array}{c}10.86 \\
(0.91 ; 11.38)\end{array}$ & $7.81(6.08)$ & $\begin{array}{c}10.71 \\
(2.71 ; 11.67)\end{array}$ & $8.25(8.65)$ & $\begin{array}{c}4.70 \\
(1.58 ; 16.09)\end{array}$ & $0.00(0.00)$ & $\begin{array}{c}0.00 \\
(0.00 ; 0.00)\end{array}$ \\
\hline MT (\%) & $20.91(15.70)$ & $\begin{array}{c}20.59 \\
(9.18 ; 30.99)\end{array}$ & $14.77(13.91)$ & $\begin{array}{c}14.19 \\
(3.49 ; 22.06)\end{array}$ & $18.93(17.19)$ & $\begin{array}{c}26.08 \\
(1.58 ; 28.59)\end{array}$ & 4.95 (8.69) & $\begin{array}{c}0.72 \\
(0.58 ; 2.94)\end{array}$ \\
\hline ST $(\%)$ & $69.06(22.71)$ & $\begin{array}{r}78.83 \\
(61.11 \\
84.92) \\
\end{array}$ & $73.59(16.90)$ & $\begin{array}{c}77.94 \\
(65.46 ; 78.06)\end{array}$ & $69.96(15.93)$ & $\begin{array}{c}65.81 \\
(62.78 ; 72.01)\end{array}$ & $68.45(18.74)$ & $\begin{array}{c}65.20 \\
(58.52 ; \\
78.37)\end{array}$ \\
\hline
\end{tabular}




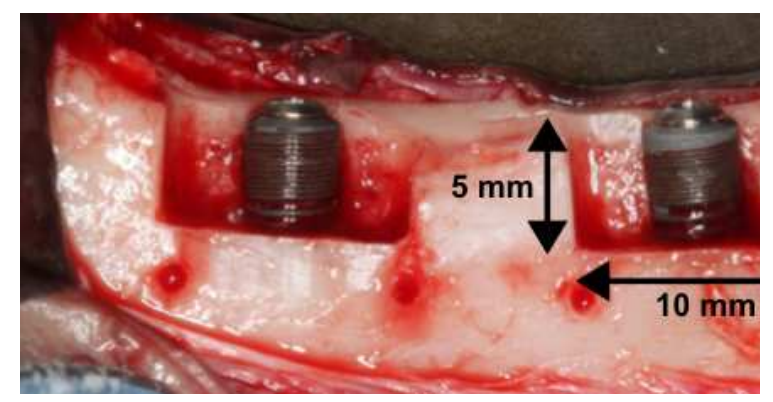

Fig. 1a

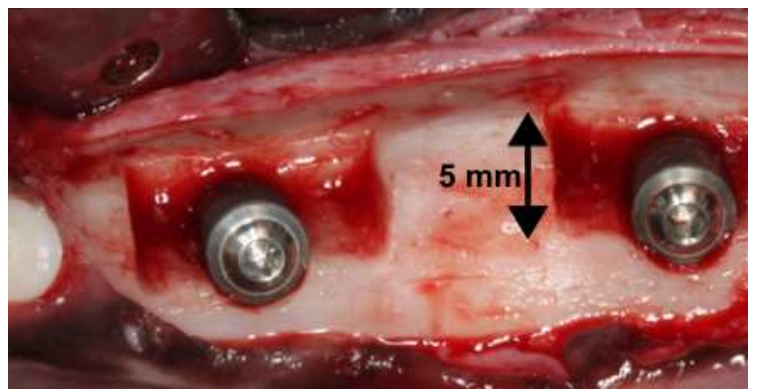

Fig. 1b

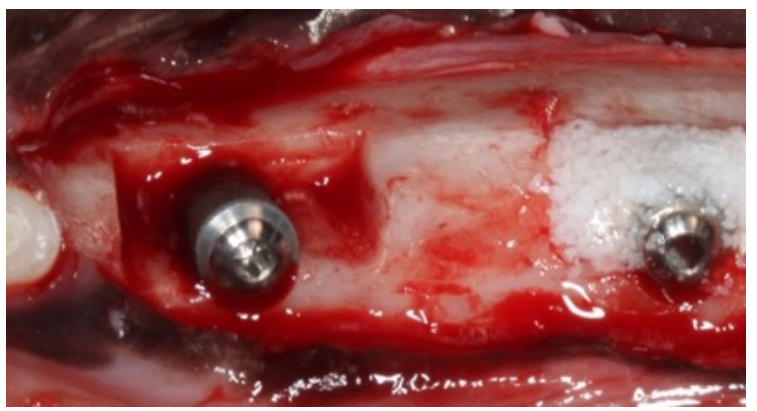

Fig. 1c

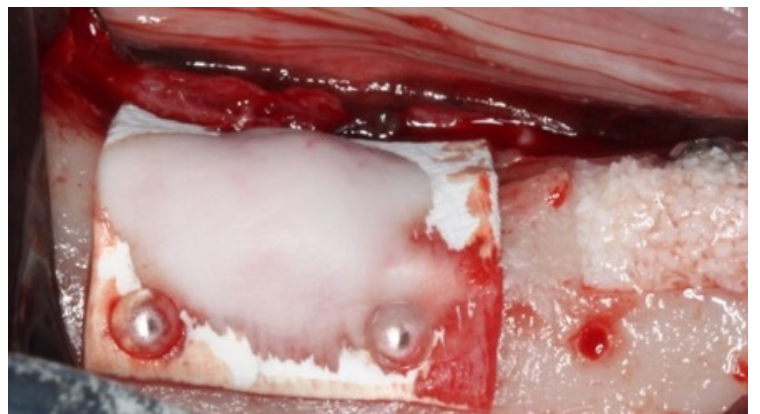

Fig. 1d

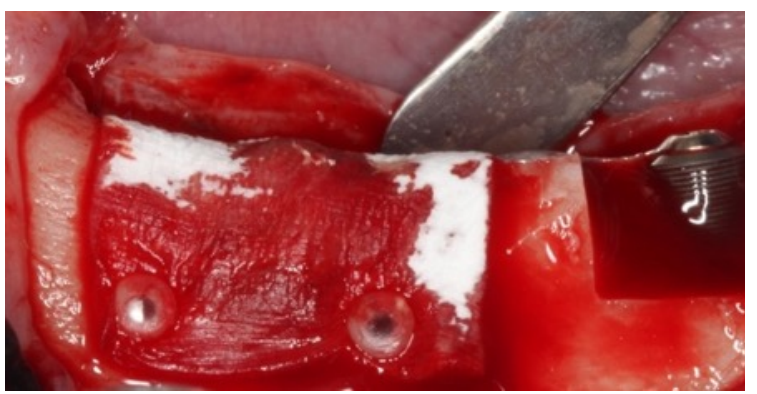

Fig. 1e 


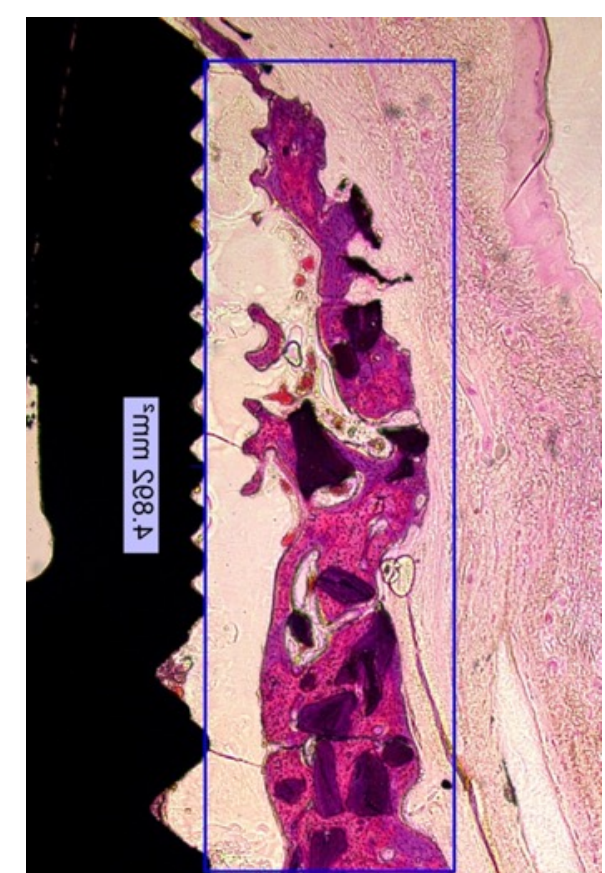

Fig. 2a

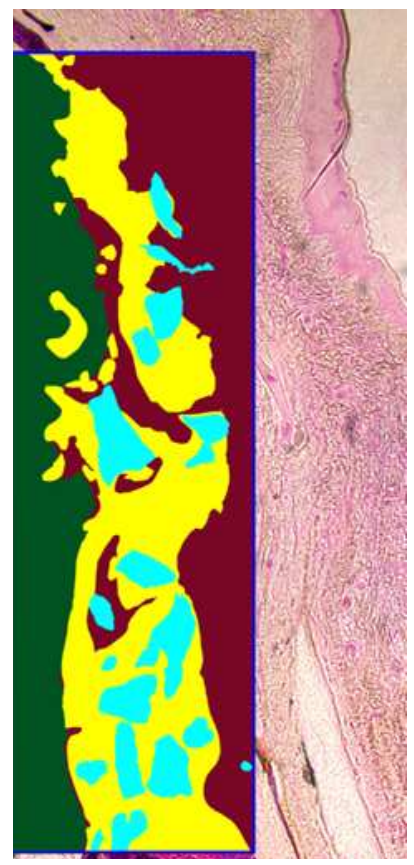

Fig. 2c

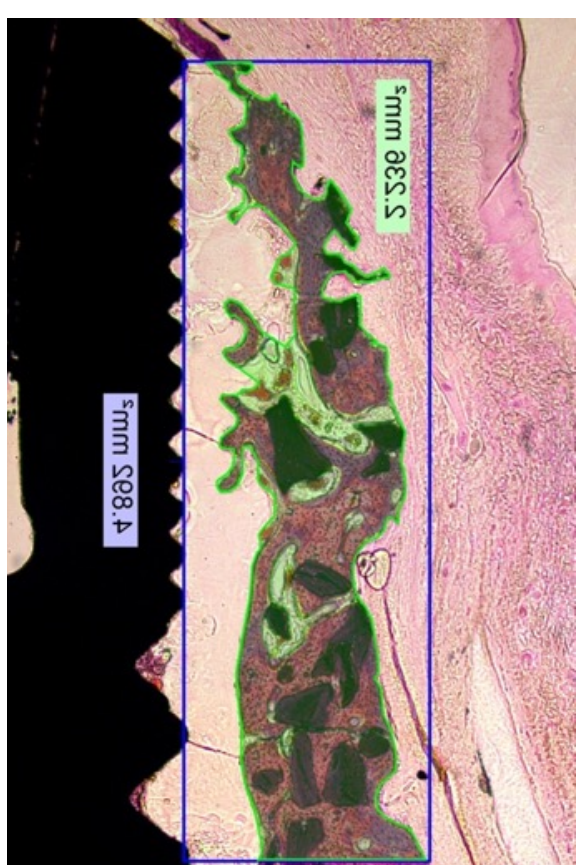

Fig. 2b 


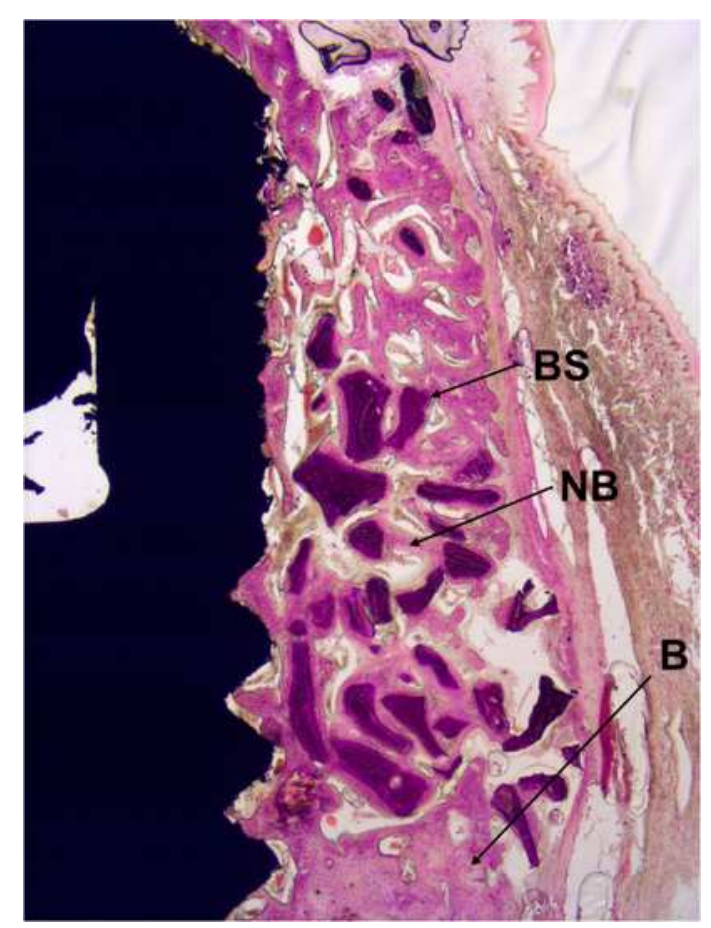

Fig. 3a

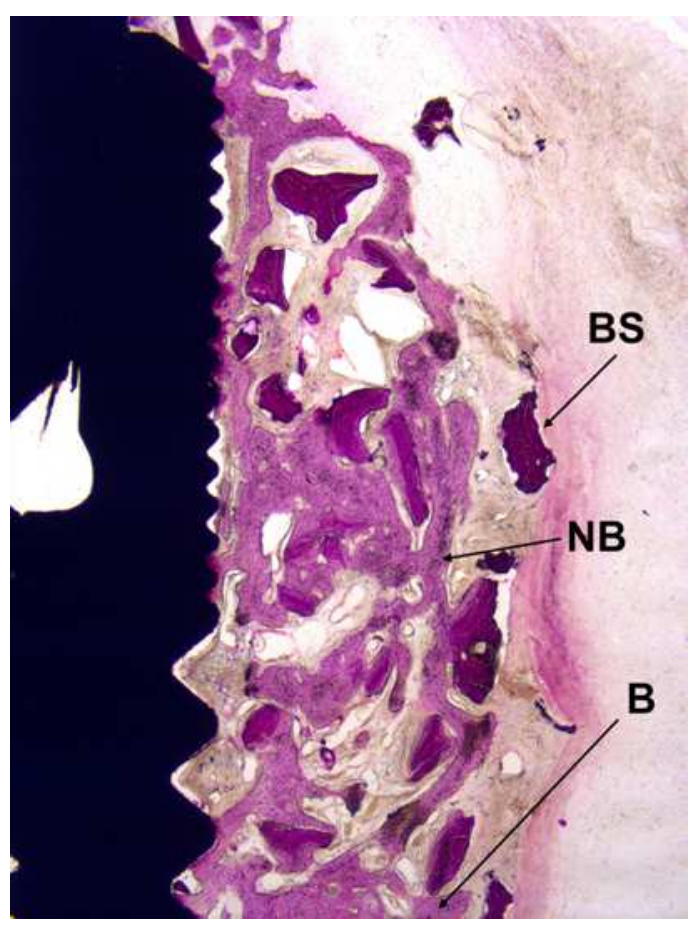

Fig. 3b

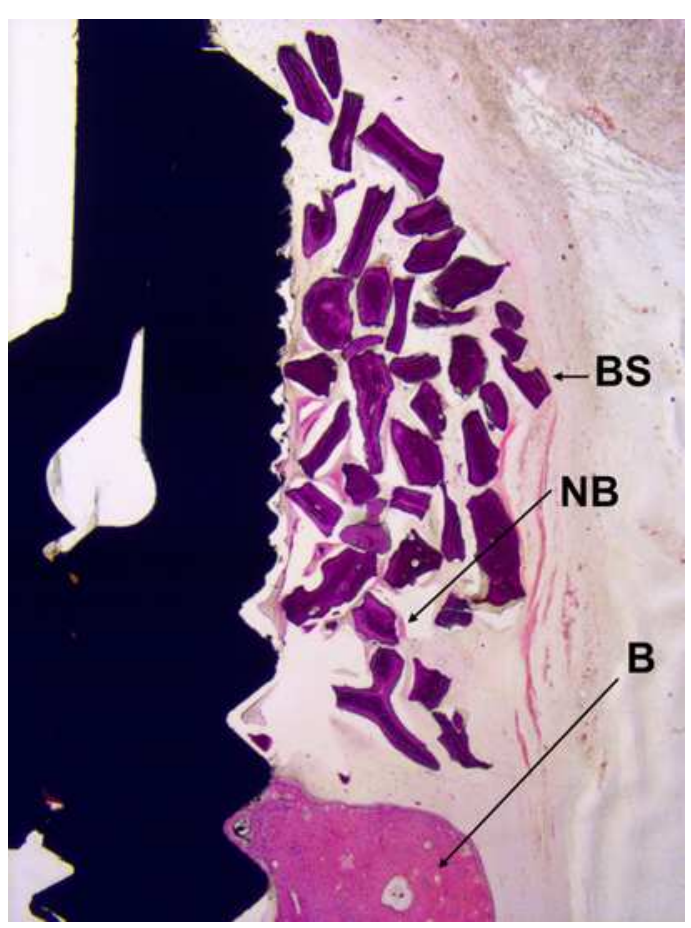

Fig. 3c

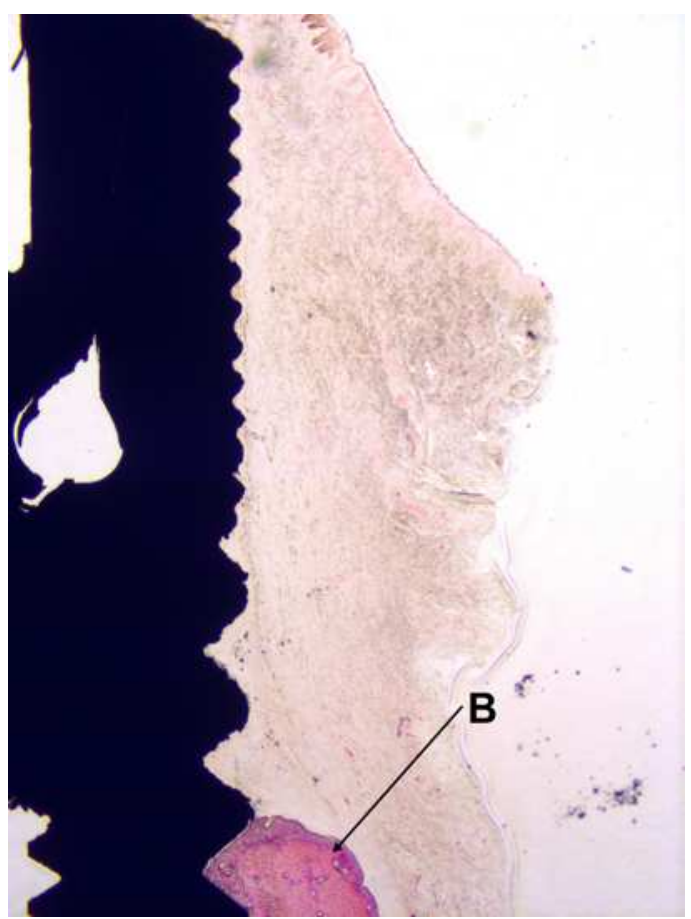

Fig. 3d 


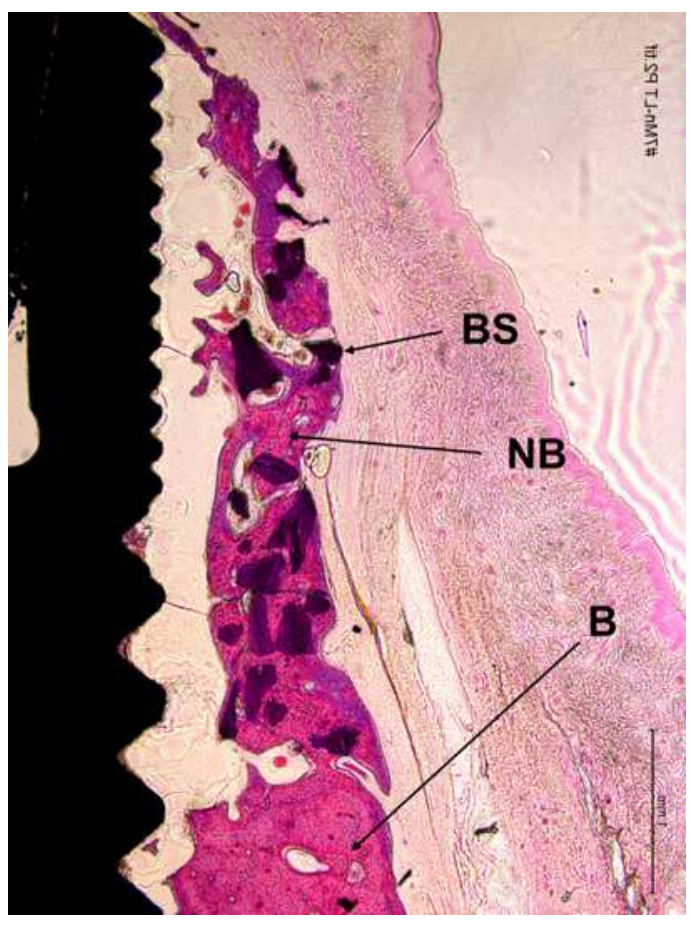

Fig. 4a

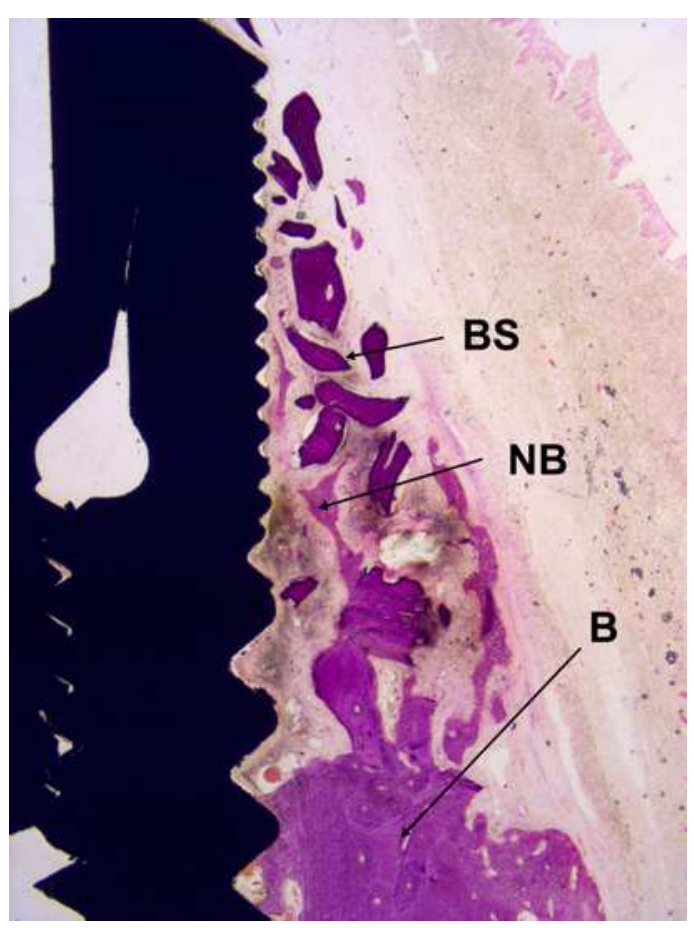

Fig. $4 b$

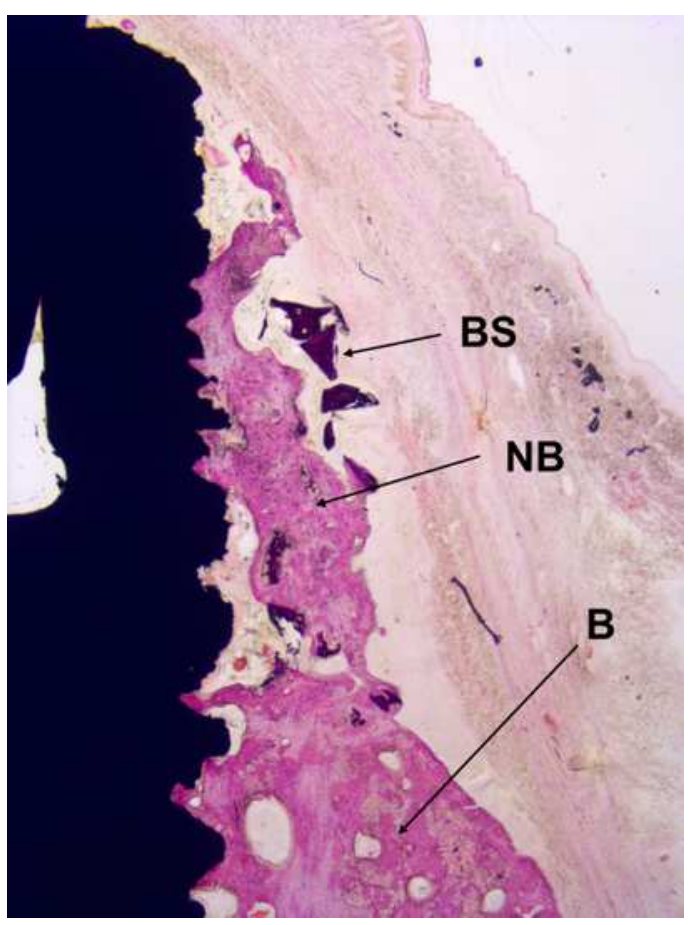

Fig. 4c

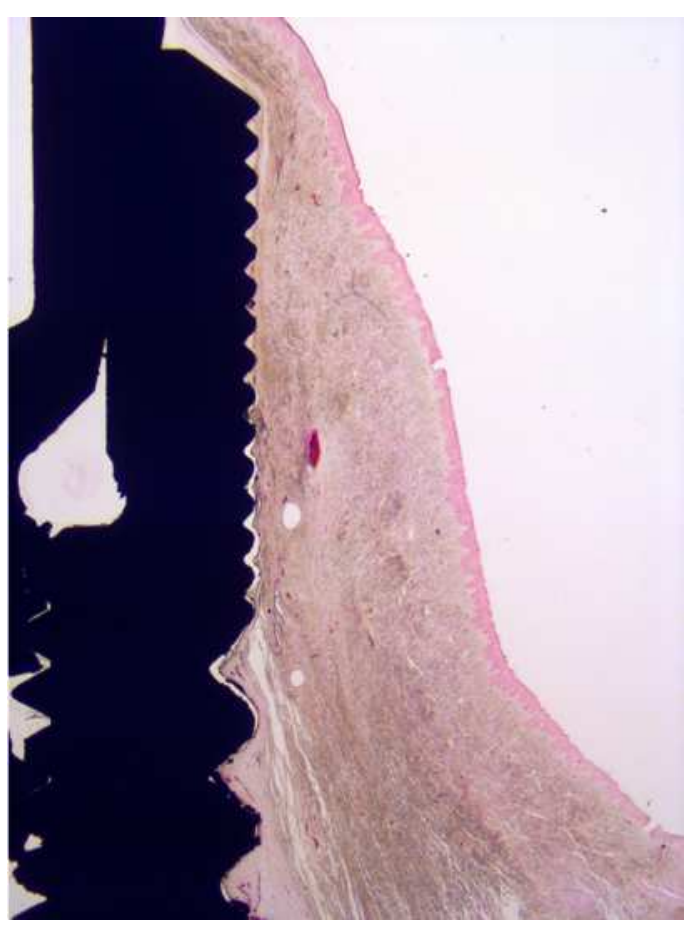

Fig. 4d 